\title{
CIÊNCIA E EDUCAÇÃO: A PROPÓSITO DO BICENTENÁRIO DO NASCIMENTO DE CHARLES DARWIN
}

\author{
ANGEL Pino*
}

\begin{abstract}
RESUMO: Este artigo visa à evocação da memória do grande naturalista e cientista britânico Charles Darwin no bicentenário do seu nascimento. A melhor maneira de evocar sua memória é trazer à reflexão dos leitores as ideias de suas três obras maiores: $A$ origem das espécies (1859), A descendência do homem (1871) e $A$ expressão das emoçóes no homem e nos animais (1872). Após apresentar a importância e a oportunidade de Darwin no debate contemporâneo, o texto inicia com uma rápida referência aos antecedentes históricos da "teoria da evolução" e às reações que ela produz. Na sequência, a obra de Darwin é situada no contexto histórico da sua época. Apresenta-se também um breve histórico das três obras maiores e uma análise das suas principais ideias. Conclui-se o texto com uma indicação sumária de algumas questões que as ideias de Darwin colocam à ciência contemporânea e, em especial, à reflexão no campo da Educação.
\end{abstract}

Palavras-chave: Charles Darwin. Evolução. Biologia e cultura. Natureza humana. Educação.

SCIENCE AND EDUCATION: ABOUT Charles DarWIN's 200 ${ }^{\mathrm{TH}}$ BIRTHDAY

ABSTRACT: This paper evokes the memory of the British naturalist and scientist, Charles Darwin on his $200^{\text {th }}$ birthday. The best way to do so is to invite our readers to reflect on some ideas of three books of his: The origin of species (1859), Descent of man (1871) and The expression of emotions in man and animals

Doutor em Psicologia e professor livre-docente (aposentado) da Faculdade de Educação da Universidade Estadual de Campinas (UnICAMP). E-mail: apino@unicamp.br 
(1872). After presenting the importance and appropriateness of Darwin in the contemporaneous debate, the text rapidly explores the historical precedents of the so called "theory of evolution" and the reactions to it. It then situates Darwin's works in its historical context and presents a brief history of these three books and an analysis of their main ideas. As a conclusion, it summarizes how Darwin's ideas question contemporary science and, more particularly, the reflection in the field of education.

Key words: Charles Darwin. Evolution. Biology and culture. Human nature. Education.

\section{Introdução}

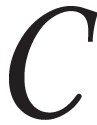

omo tem siso divulgado pela mídia nacional e internacional, o mundo científico comemora, neste ano de 2009, o segundo centenário do nascimento do grande naturalista e cientista inglês Charles Darwin (1809-1882) e os 150 anos da sua famosa obra On the origin of species by means of natural selection (1859). ${ }^{1} \mathrm{Nada}$ mais oportuno, então, que a revista Educação \& Sociedade dedique, no seu número especial de 2009, algumas páginas que lembrem essa dupla efeméride. Não como uma mera formalidade comemorativa, mas como uma oportunidade para trazer à reflexão o significado que as questões levantadas dois séculos atrás pela teoria da "evolução das espécies" pode ter para o pensamento contemporâneo e, de modo particular, para a Educação. Se seus trabalhos se situam mais diretamente no campo das chamadas Ciências Naturais, mais especificamente as biológicas, eles envolvem questões que, mesmo na sua época, ultrapassavam os limites desse campo, levantando questionamentos no campo das Ciências $\mathrm{Hu}$ manas, ${ }^{2}$ em razão de centrar no homem o objeto das investigações. Com efeito, não são apenas as peripécias que ocorrem no mundo dos seres vivos, identificados como expressão da natureza, que são o objeto dos trabalhos de Darwin, mas as peripécias de uma espécie particular desses seres vivos, o homem, cuja origem as tradições dos povos situam fora da natureza. Ao resituar o homem dentro da natureza e sujeito aos mesmos princípios evolutivos de todas as outras espécies vivas, Darwin quebrou essas tradições, tornando-se, por suas ideias, ainda em vida, o alvo da admiração de alguns, poucos, e da rejeição de outros, muitos. Fenômeno que, na comemoração bicentenária do seu nascimento, tende 
a repetir-se em dimensões diferentes, mas por razões semelhantes. É o embate entre ciência e fé religiosa, entre razão e crença. A comemoração da obra de Darwin aparece, certamente, como uma oportunidade para refletir no campo da Educação sobre a significação que sua obra pode ter para o homem de hoje e a sociedade contemporânea.

O conceito de educação, como é entendido aqui, tem dois sentidos diferentes, porém, complementares. Um, mais abrangente, é o relativo ao processo de constituição e formação das pessoas humanas, ${ }^{3} \mathrm{o}$ que, de regra, ocorre na sua inserção na vida social e cultural do meio humano. O outro, mais restrito, é o relativo ao acesso ao conhecimento científico e tecnológico produzido ao longo da história humana, o que, de regra, ocorre na instituição social da escola. Integram-se, nesse duplo sentido de educação, tanto o acesso ao conhecimento do universo - sua origem, formação e evolução - quanto o acesso ao conhecimento da natureza humana do homem - sua origem, história, características biológicas e culturais e seu papel na sua própria constituição como ser humano. Constituição que envolve a possibilidade de transpor os limites de sua evolução biológica, abrindo-se para o universo do cultural e do simbólico. Se a evolução biológica parece ter atingido no homem o patamar do possível na natureza, a evolução cultural e simbólica aponta para patamares cujos limites reais são difíceis de prever. Daí a importância de se recolocar algumas das questóes postas pela obra de Darwin, que tanta polêmica levantou e ainda levanta nos mundos da ciência e da consciência.

É certo que não se pode esperar da teoria da evolução de Darwin resposta a todos os problemas que levantou e dos quais, possivelmente, ele mesmo não tivesse ideias claras. Apesar da sua enorme importância, tal teoria é limitada pelas próprias condições de produção no século XIX, tornando-se, porém, cada vez mais sólida pela contribuição de importantes pesquisas contemporâneas. Mas suas ideias pioneiras têm muito a oferecer à reflexão de problemas que ainda escapam aos cientistas sobre a própria natureza humana do homem. Este ser que, sendo semelhante aos outros seres vivos, de cuja trajetória evolutiva participa, é enormemente diferente em razão das funções e habilidades novas que adquiriu ao longo da sua história e que a evolução natural só não outorga. Não é de se surpreender, portanto, que o homem tente penetrar, ao mesmo tempo, nos espaços siderais mais distantes do universo 
e nas profundidades moleculares da vida para desvendar seus mistérios. O surpreendente é o pouco que ele ainda sabe de si mesmo, dessa sua condição humana de ser que vem construindo sem prestar suficiente atenção a isso e cuja ignorância pode até comprometer sua promissora caminhada de progresso. É nesse contexto de questões que se situa este trabalho, cujo objetivo é tentar apontar algumas possíveis linhas de reflexão sobre a contribuição da obra de Darwin no campo da Educação. Dada a abundante produção de Darwin e a extensão da maioria das suas obras, nossa atenção concentrar-se-á, neste trabalho, em três dessas obras, as quais formam certa unidade: as de 1859 , de 1871 e de 1872 .

\section{Antecedentes históricos da teoria da evolução}

Como o mostra a história dos povos antigos de que se tem conhecimento - das mais remotas sociedades tribais às grandes civilizações antigas (como as dos egípcios, babilônios, persas, gregos e romanos) -, a preocupação com as questóes das origens do mundo, dos seres vivos e do homem é tão antiga quanto o próprio homem. Essa preocupação aparece, de diferentes maneiras, na história desses povos, de acordo com suas tradiçõoes e sistemas de ideias e crenças. Sistemas estes variáveis, mas que se situam no espaço intermediário de dois pólos: o dos sistemas mitológicos, mais visíveis nas sociedades tribais primitivas, e o dos sistemas religiosos de tipo monoteísta. O que as tradições de todos esses povos antigos têm em comum é a procura, no "mundo do sagrado" - morada mítica dos deuses, onde não existem nem alegria nem dor, nem ordem nem desordem, por lá não haver lugar para a lei e o interdito -, de resposta às questôes que levanta sua existência no mundo do real, ou "mundo profano" - morada real do homem, regida por normas, leis e interditos. São estes mundos opostos de que falam antropólogos e filósofos estudiosos das religióes e das mitologias (Mircea, 1963; Caillois, 1963, 1972; Makarius, 1974; Girard, 1972). Tais mitos e crenças fazem parte constitutiva da história e das tradições dos povos, antigos e modernos.

Dentre os povos antigos tem um lugar de destaque, pela sua tradição religiosa monoteísta, o povo hebreu, descendente da família de Abraão (século XIX a.C.), oriundo de Ur (antiga Mesopotâmia) e chefe de um clã dedicado ao pastoreio que migrou à região de Canaã à procura de pastos para os seus rebanhos. Segundo o Gênese (12, v. 1-3; 17, v. 1-21), foi com Abrão que Yavé selou uma aliança: fazer da sua 
descendência um povo numeroso, ao qual daria uma terra rica e fértil, com a condição de permanecer fiel a seu Deus, senhor e criador do mundo e de tudo que o habita. A crença de ser "o povo eleito" e a esperança na "terra prometida" tornaram-se elementos fundamentais do projeto histórico dos hebreus, de cuja aliança se tornou herdeira a pequena comunidade surgida, nos últimos tempos da dominação romana, em torno do Messias anunciado pelos profetas hebreus. O reconhecimento, pelo imperador romano Constantino (Edito de Milão, 313), da religião dessa comunidade messiânica como religião de Estado fez dela a Igreja Católica Romana que, apesar de variadas dissidências ao longo dos séculos, estendeu seu poder pelo mundo conhecido, marcando a história e o pensamento ocidentais. Essa é uma das razões, senão a principal, de que só a partir do século XVIII - à exceção de poucos casos ocorridos em épocas anteriores - cientistas começassem a sustentar ideias sobre a origem do mundo e a evolução das espécies, contrárias ao pensamento cristão sobre a criação do mundo e do homem.

\section{As ideias sobre a evolução no tempo de Darwin}

Embora sejam numerosos os cientistas que, nos séculos XVIII e XIX, se colocavam questões próximas às que se colocara Charles Darwin, serão lembrados apenas alguns: primeiro aqueles cujas ideias precederam, de alguma forma, às de Darwin; e, segundo, aqueles que, de alguma forma, acompanhavam de perto suas pesquisas, tornando-se seus interlocutores.

Dentre os primeiros, cabe lembrar, inicialmente, o naturalista francês Georges-Louis Leclerc, Conde de Buffon (1707-1788), autor da monumental e enciclopédica Histoire naturelle, généralle et particulière, em cujos 44 volumes, alguns publicados após sua morte, trata dos conhecimentos de História Natural existentes até então. Nessa obra expõe ideias sobre as semelhanças e diferenças existentes entre os seres vivos e, o que é mais interessante, as semelhanças entre o homem e o macaco, chegando à hipótese da existência de um ancestral comum a ambos. Ideia esta altamente comprometedora para quem temia enfrentar as críticas dos teólogos da Sorbonne. Em Les epoques de la nature (1788), seu livro póstumo integrante da obra, ele parece ter recuado de forma a amenizar tais ideias, adotando, porém, posições no mínimo curiosas. De um lado, apresenta uma visão nada ortodoxa sobre o sistema solar e a origem dos 
planetas por colisão de cometas com o sol, colidindo assim com a visão cosmológica da filosofia cristã. De outro lado, sustenta a ideia de "gradualismo" nas mudanças geológicas, semelhante à teoria que o geólogo Charles Lyell apresentaria 40 anos depois, em Principios de geologia (1833). Trata-se de teoria concordante com o criacionismo. Segundo o biólogo alemão Ernst W. Mayr (1904-2005), o paradoxo de Buffon é que "ele não foi um evolucionista, mas foi o pai do evolucionismo. Foi a primeira pessoa a discutir um grande número de problemas evolutivos, problemas que antes de Buffon ninguém levantou (...) ele os expôs à atenção do mundo científico" (1981, p. 335). Em razão disso, Darwin só teria admitido o valor científico das ideias de Buffon sobre a evolução em 1866, referindo-se a ele como o primeiro que, nos tempos modernos, tratou a evolução com espírito científico.

Outro nome importante nas ciências biologias do século XVIII foi o botânico e zoólogo sueco Carolus Linnaeus (1707-1778). Embora nos seus primeiros escritos tivesse uma visão ortodoxa sobre a imutabilidade das espécies, suas observaçōes posteriores o levaram a admitir que elas variavam. Seu prestígio científico devia-se a seu intenso trabalho de elaboração e de sistematização de métodos e nomenclaturas para organizar e classificar os organismos vivos da fauna e da flora. Foi quem introduziu as categorias de gênero e espécie. Suas pesquisas fazem parte da sua obra Systema naturae, cuja primeira edição, de 1735, de poucas páginas, foi sendo engrossada nas sucessivas edições com os resultados de novas pesquisas.

Outro nome que influenciou as ideias do jovem Charles foi seu avô, o naturalista Erasmus Darwin. Baseado nas observações das mudanças ocorridas em animais durante o desenvolvimento (p. ex., a crisálida em borboleta), em plantas em cultivo, animais em fase de domesticação, em vestígios de órgãos rudimentares, em cruzamento de indivíduos de diferentes espécies, assim como em semelhanças anatômicas observadas em muitas delas, ele chegou à conclusão de que a evolução existia. $\mathrm{O}$ curioso é que imaginava que essas mudanças eram devidas a fenômenos que hoje chamaríamos emocionais (tais como sofrimento e prazer, desejo e repulsão etc.), vistos como origem de mudanças comportamentais da aquisição de novas funções ou órgãos.

Ideias parecidas a essas foram desenvolvidas, de forma independente, por Jean-Baptiste de Lamark (1774-1829), o qual, devido à dificuldade de distinguir as diferenças entre as espécies, concluiu que 
não se observava diferença real entre elas, a menos que fossem submetidas a um estudo comparativo. Reconhecendo mais tarde que errou nisso, Lamarck admitiu que, mesmo sendo difícil detectá-las, as barreiras entre as espécies efetivamente existiam. Em 1809, Lamarck pensou que tinha condições de propor um modelo evolutivo e criar uma árvore genealógica que ligasse todas as espécies, dos microorganismos ao homem, especulação que ele teria abandonado por não encontrar sustentação a seus pontos de vista.

Dentre os cientistas que constituíam o que chamamos de "grupo restrito", destacaram-se alguns. Em primeiro lugar, Jhon Stevens Henslow (1795-1861), geólogo e botânico, professor de Ciências Naturais na universidade de Cambridge, do qual Darwin foi aluno quando fazia o Curso de Artes. Reconhecendo o grande interesse de Darwin pelas pesquisas em Ciências Naturais, Henslow o indicou a R. Fitzroy, capitão do navio Beagle, da marinha real, para acompanhar como naturalista a expedição que ia fazer pela América Latina para mapear suas costas. Foi nessa expedição, que acabou alongando-se por cinco anos (1831-1835), que Darwin colecionou um grande arsenal de informaçôes, dados e registros sobre as condições geológicas, a fauna e a flora do continente sul-americano, assim como de alguns dos seus habitantes. Destacam-se as pesquisas nas ilhas Galápagos, nas costas de Chile. Enquanto Darwin navegava, enviando parte de seus registros para a Inglaterra, Henslow cuidava da reputação do seu pupilo entre os naturalistas ingleses. Isso permitiu que, ao seu retorno à Inglaterra, em outubro de 1836, já fosse considerado uma celebridade no meio científico. Muitas das suas primeiras análises foram tornadas públicas no seu diário da viagem e em seus comentários, no livro The voyage of the Beagle (1939), publicado pelo capitão Fitzroy.

Um jovem cientista com quem Darwin compartilhou as ideias que vinha elaborando sobre as espécies e sua evolução foi o botânico Joseph Dalton Hooker, seu amigo e auxiliar num estudo sobre "cracas". Foi a quem Darwin confiou a leitura e comentários do seu Ensaio (1848), onde apresentava suas pesquisas iniciadas em 1831, na viagem do Beagle. Os comentários do amigo e cientista ajudaram a aumentar a aceitação externa das suas ideias.

Um caso particular e curioso foi o de Alfred Russel Wallace (18231913), ${ }^{4}$ emérito naturalista, geólogo e biólogo britânico. Enquanto fazia pesquisas nas ilhas Molucas (Índia), enviou a Darwin, com quem 
mantinha correspondência, um "ensaio" onde apresentava sua teoria da evolução, pedindo-lhe uma avaliação e posterior envio a Charles Lyel, geólogo e amigo comum. Percebendo a grande semelhança da teoria da evolução de Wallace com a sua, na qual vinha trabalhando em sigilo durante muitos anos, informou a Lyel da sua preocupação. Diante dessa situação, Lyel e Hooker, influentes no mundo científico, propuseram que as duas teorias fossem apresentadas ao mesmo tempo, no Centro de Estudos de História Natural, o Linnean Society of London, o mais importante da Inglaterra. Isso ocorreu em julho de 1858. Depois disso, Lyel aconselhou Darwin a publicar o mais rapidamente possível $A$ origem das espécies, por razōes da concorrência. $\mathrm{O}$ livro foi publicado no ano seguinte (1859).

Sua publicação provocou uma grande controvérsia que ele acompanhou, recolhendo tudo o que era publicado a respeito. Houve reações contrárias ao livro, como a de Richard Owen, expoente do meio cientifico, e o grupo de cientistas ligados à Igreja da Inglaterra, incluindo os antigos tutores de Darwin na universidade de Cambridge, Adam Sedgwick (1785-1873) e J. L. Henslow, porque suas ideias representavam uma negação da verdade da criação. Mas não houve só críticas. Artigos e resenhas favoráveis às suas ideias apareceram em diferentes publicações. Um dos mais ardorosos defensores da sua teoria da evolução foi Thomas $\mathrm{H}$. Husley (1825-1895), ${ }^{5}$ grande biólogo inglês da cúpula dos cientistas britânicos, que ficou conhecido como o "Buldogue de Darwin", pelo ardor na sua defesa pública no The Times. Mas foi no grande debate científico sobre a "Evoluçãa", ocorrido na Universidade de Oxford (junho de 1860), que ele teve seu grande confronto com Samuel Wilbeforce (1805-1873), o conservador bispo de Oxford, e Richard Owen, seu acólito. Talvez tenha sido o maior confronto no século XIX entre ciência e religião. Referindo-se mais tarde a esse debate, Darwin teria afirmado que era de grande importância mostrar ao mundo que uns poucos homens de primeira linha nas ciências não tinham medo de expressar sua opinião.

Charles Lyell (1797-1875), geólogo e amigo de Darwin, desenvolveu uma teoria que explicava as mudanças geológicas da terra pelo princípio da "gradualidade" (mudanças graduais), denominado de "uniformitarismo", "que se contrapunha ao de mudanças bruscas, por efeito das catástrofes, denominado de "catastrofismo". Ambos os princípios, apesar de opostos, constituem variantes do criacionismo, perspectiva cristã. Lyel publicou suas ideias no seu livro Principios de Geologia 
(1833), recebido e lido por Darwin durante a viagem no Beagle. Parece que, inicialmente, Darwin teria gostado das ideias nele expostas, embora mais tarde acabasse discordando delas.

\section{As grandes obras de Darwin em estudo}

Como já foi dito anteriormente, nossa atenção concentrar-se-á naquelas três grandes obras que, sem dúvida alguma, constituem um conjunto relativamente articulado das questões fundamentais que sintetizam a totalidade de sua produção, as quais, podemos dizer, se alimentam das pesquisas que deram origem a elas. A primeira, a mais popular, o que não quer dizer que seja igualmente conhecida, é $A$ origem das espécies, cuja primeira edição é de 1859 . A segunda, menos conhecida, é $A$ descendência do homem, publicada só em 1871. A terceira, conhecida só em alguns meios acadêmicos muito restritos, é $A$ expressão das emoçôes no homem e nos animais, de 1872 . Na primeira, são apresentados os fundamentos empíricos e os princípios lógicos da origem de todas as espécies vivas, ou seja, da teoria geral da evolução. $\mathrm{Na}$ segunda, Darwin tenta mostrar que a origem do homem se situa na mesma linha da evolução geral das espécies, analisando as características que fazem dele uma espécie mais avançada que as outras e, por isso mesmo, mais complexa. Na terceira, sobre as emoçóes no homem e nos animais, traz aspectos novos que mostram com profusão de detalhe as semelhanças e diferenças da espécie humana em relação aos animais, em particular os outros descendentes dos primatas. A obra permite ao mesmo tempo penetrar nesse "mundo interior" das emoções e dos afetos, fonte fundamental da vida. As três obras formam um conjunto integrado, sendo que a segunda e a terceira constituem uma espécie de elementos de prova da origem evolutiva da espécie humana. Apesar de sua articulação, $A$ origem das espécies foi a que causou a grande polêmica, despertando, desde a sua publicação, a admiração de uns e a profunda reação negativa de outros.

A análise da extraordinária quantidade de dados empíricos coletados durante os cinco anos da viagem no Beagle permitiria a Darwin convencer-se de duas coisas: primeiro, que na natureza existe uma variedade ilimitada de espécies e de variações entre as que formam um mesmo gênero; segundo, que as espécies mudam ao longo de gerações, dando origem a outras espécies e que sua evolução ocorre por "seleção 
natural". Não bastava, porém, ter a convicção que esses dados lhe proporcionavam, era necessário ter sua comprovação científica:

Ao considerar a Origem das Espécies, é perfeitamente concebível que um naturalista, ao refletir sobre as mútuas afinidades dos seres orgânicos, de suas relações embriológicas, sua distribuição geográfica, sua sucessão geológica e outros fatos semelhantes, possa chegar à conclusão de que cada uma das espécies não foi criada independentemente, mas descende como uma variedade de outras espécies. Todavia, tal conclusão, mesmo se bem fundada, seria insatisfatória até que fosse possível mostrar como as inúmeras espécies que habitam este mundo foram modificadas até adquirir essa perfeição de estrutura e co-adaptação que com toda razão excita nossa admiração. $(1859, \text { p. } 3)^{7}$

\section{A origem das espécies (1859)}

Não sabemos grande coisa do que o jovem estudante Darwin pensava a respeito das questôes que o tornariam famoso três décadas depois de partir, como naturalista, na expedição do Beagle, em 1831. Mas suas palavras na introdução de $A$ origem das espécies revelam que ele pensava como a imensa maioria dos naturalistas até então. Isso só mudaria quando começasse a fazer as análises do enorme arsenal de observações e dados registrados durante a longa travessia: "Eu não posso ter dúvida, após o mais ponderado estudo e julgamento desapaixonado de que sou capaz, de que a visão que tem a maior parte dos naturalistas e que eu tinha antes - a saber, que cada uma das espécies foi criada independentemente - é errônea" (1859, p. 6). ${ }^{8}$

Por que é errôneo pensar que as espécies foram criadas independentemente umas das outras? A razão é simples. Se isso fosse certo, significaria que: (1) cada uma delas seguiria um padrão próprio de características anatômicas, fisiológicas e funcionais, outorgado pelo seu criador; (2) esse padrão não variaria ao longo dos tempos, de forma que as espécies seriam diferentes, mas sem nenhuma semelhança de componentes; e (3) as espécies não constituiriam, logicamente, nem gêneros nem sistemas; pelo contrário, formariam uma infinidade de conjuntos de indivíduos, diferentes e independentes, coabitando um mesmo território. Ora, das costas da América do Sul às da Austrália e da Polinésia, a realidade que se apresentava ao jovem e ainda pouco experiente Darwin 
desmentia tal visão. O que ele observava, mesmo como um simples estudante de História Natural, era muito diferente. De um lado, evidências de "mudanças" geológicas em diferentes regióes visitadas pelo Beagle, algo que ele aprendeu a observar após a leitura dos trabalhos do grande geólogo Charles Lyell, que já tinha demonstrado isso antes. De outro lado, a imensa diversidade de espécies, animais e vegetais, que povoavam os continentes visitados. Diversidade de espécies e de indivíduos em cada uma delas que, ao mesmo tempo, apresentavam semelhanças importantes. Isso mostrava claramente que cada uma delas não podia ter sido criada independentemente. A suspeita de existir tal discordância foi tornando-se, para Darwin, uma certeza cada vez mais sólida: a de que as espécies não são imutáveis, mas mudam no processo evolutivo que as ligam e, ao mesmo tempo, as separam de outras das quais descendem. A percepção da existência dessa discordância consolidava nele a idéia da evolução. As observações geológicas das regiōes percorridas e as observações das espécies que as povoavam mostravam que nada do que existe é imutável e que o mundo muda e as espécies evoluem.

Estou plenamente convencido - afirma Darwin - de que as espécies não são imutáveis; sendo que as que pertencem ao que é considerado um mesmo gênero são descendentes diretas de outras espécies, geralmente extintas, do mesmo modo que as variedades conhecidas de uma dada espécie descendem dessa mesma espécie. Mais ainda, estou convencido de que a Seleção Natural tem sido o principal meio, não exclusivo, da mudança. (idem, p. 6) ${ }^{9}$

Os pontos fundamentais da discordância entre as ideias dos naturalistas da sua época e a realidade que ele, Darwin, observava por toda parte constituem os temas dos vários capítulos do livro: 1) as espécies existentes não foram criadas cada uma de forma independente; 2) elas não são imutáveis, mas mudam ao longo do tempo; 3) as mudanças que ocorrem nelas são resultado de um processo lento, de pequenas diferenças, que num certo momento se consolidam; 4) a seleção natural - que Darwin compara aos efeitos da domesticação de animais e do cultivo de plantas pelos homens - constitui o principal meio de mudança, embora não seja o único; 5) a seleção natural opera em dois níveis diferentes, mas convergentes: o da competição entre as espécies e entre os indivíduos de uma mesma espécie e o da luta pela 
$v i d a,{ }^{10}$ expressão metafórica que traduz os efeitos do crescimento desigual das espécies e dos indivíduos em relação às condiçōes de sobrevivência. Como ele diz: "A luta pela vida decorre inevitavelmente das altas taxas de crescimento a que tendem todos os seres vivos. Quanto maior for o número dos que sobrevivem, maior será a luta pela existência. É a doutrina maltusiana, que se aplica com maior força aos reinos animal e vegetal" (1859, p. 63).

Encerrando o livro com a recapitulação de algumas das principais questôes tratadas, ele destaca três: 1 ) as dificuldades da teoria da "seleção natural" e das circunstâncias gerais e específicas em seu favor; 2) as causas da crença na imutabilidade das espécies; e 3) a maneira como essa teoria pode ser estendida e os efeitos que produziria sua adoção no estudo da História Natural.

Em relação ao primeiro item, Darwin reconhece a dificuldade de aceitar que órgãos e instintos mais complexos possam ter chegado à perfeição a que chegaram sem a ação de um meio superior à razão humana, mesmo que seja análogo, mas pela acumulação de inumeráveis pequenas variações, boas para o seu possuidor. Entretanto, diz ele, "mesmo parecendo à nossa imaginação uma grande dificuldade, não pode ser considerada real" (p. 459), pelas razōes expostas ao longo do livro.

Em relação ao segundo item, retoma o que parece ter sido sua grande e constante indagação: Por que cientistas dos mais eminentes parecem estar satisfeitos com o ponto de vista de que cada espécie foi criada independentemente? Darwin reconhece que foram recapitulados os fatos principais que o convenceram profundamente de que as espécies mudaram e que continuarão mudando lentamente pela preservação e acumulação de sucessivas pequenas variações favoráveis a elas. Contudo, afirma: "A causa principal de nossa natural relutância a admitir que uma espécie tenha dado origem a outra espécie distinta é que sempre somos lentos em admitir cada grande mudança da que não vemos as etapas intermediárias" (p. 481).

Será que é essa a razão principal? Ou será que, como ele diz, a mente não pode compreender o pleno significado do que seja um grande período, como "quinhentos milhōes" de anos? Ou, ainda, que essa mente não possa perceber todos os efeitos de algumas pequenas mudanças acumuladas num quase infinito número de geraçōes? As respostas a essas e outras indagaçōes não parecem explicar totalmente a razão 
da relutância à evolução. Talvez a resposta certa fosse que a idéia da "criação independente" das espécies é objeto de uma crença maior!

No meu entender - diz Darwin - isso combina melhor com o que conhecemos a respeito das leis impressas na matéria pelo Criador, de forma que a produção e extinção dos habitantes do mundo no passado e no presente teriam sido devidas a causas secundárias, como as que determinam o nascimento e a morte do indivíduo. (p. 488)

\section{A descendência do homem (1871)}

A questão da origem e descendência do homem não teria porque ser tratada em separado da questão da evolução geral das espécies, pela simples razão de que, como tal, os humanos devem estar incluídos na evolução geral de todas as espécies. Essa parece ter sido a intenção de Darwin, como diz na introdução da obra:

Durante muitos anos reuni notas sobre a origem e descendência do homem, sem a intenção de publicar algo sobre esse assunto, mas antes com a determinação de não publicar, pois pensei que assim ia acrescentar prejuízos à minha concepção. Pareceu-me suficiente indicar, na primeira edição de minha "Origem das espécies", que por este trabalho "seria projetada luz sobre a origem do homem e sua história" e isto implica que o homem deve ser incluído com os outros seres orgânicos, numa conclusão geral a respeito de sua maneira de aparecer nesta terra. (1871, p. 1)

Então, o que foi que o levou a mudar de decisão? Segundo ele, foi o fato de que um naturalista como Carl Vogt se aventurasse a dizer ao presidente da Instituição Nacional de Genebra, em 1869, que "ninguém, pelo menos na Europa, ousa mais sustentar a criação independente e completa das espécies". ${ }^{11}$ Isso poderia indicar que um amplo número de naturalistas já aceitaria que as espécies descendem de outras espécies modificadas. Nada mal para quem, em 1859, via que os naturalistas que pensavam assim eram uma pequena minoria. De qualquer maneira, segundo Darwin, alguns ainda pensavam que ele tinha superestimado essa questão, e muitos dos "honoráveis chefes da ciência natural”, como ele os chama, não aceitavam nenhum tipo de evolução. Esta parece ter sido a razão de retomar suas numerosas anotações sobre a evolução das espécies para ver até que ponto se aplicava ao homem. 
Como as conclusões a que chegou lhe pareciam interessantes, pensou que poderiam interessar também a outros.

Ele reconhece que a idéia de que o homem é co-descendente de outras espécies antigas, inferiores e extintas, de alguma forma, não é nova. Lamarck, por exemplo, chegou anos antes à semelhante conclusão, a qual tem sido recentemente mantida por outros eminentes naturalistas e filósofos, dentre os quais se destacam Wallace, Huxley, Lyell, Vogt, Lubbock, Büchner, Rolle e, especialmente, Häckel, de quem Darwin diz, ao falar da sua obra Natürliche Schöpfungsgeschichte (1868), sobre a genealogia do homem: "Se este livro apareceu antes do meu ensaio ser escrito, eu provavelmente nunca o teria completado. Quase todas as conclusões a que eu tenho chegado as encontro confirmadas por este naturalista, cujo conhecimento sobre muitos pontos é muito mais completo que o meu" (1871, p. 3-4).

Em $A$ descendência do homem, Darwin tem um objetivo bem claro: mostrar que a espécie humana faz parte também do fluxo evolutivo de todas as espécies, o que torna ainda mais ousada a sua tarefa, dadas as crenças míticas ou religiosas a respeito das condições peculiares da criação do homem. Mas é isso mesmo que Darwin se propõe como objeto de sua investigação: "verificar se o homem, como as outras espécies, descende de alguma forma pré-existente", como se dá "a forma do seu desenvolvimento" e qual é "o valor das diferenças entre as chamadas raças humanas" (p. 2-3). Dado o grande número de questões que ele se dispôs a tratar sobre a origem do homem, Darwin recorre a vários trabalhos publicados por outros cientistas, como, por exemplo, o de M. Boucher de Perthes, sobre "a antiguidade do homem", e o de Huxley, sobre as "diferenças entre o homem e os macacos antropomórficos", onde este autor sustenta que o homem está mais próximo destes macacos do que estes estão dos membros inferiores da mesma ordem dos primatas. Saber o papel que a "evolução sexual" desempenha no processo evolutivo das espécies, comparando a espécie humana com as outras espécies, assunto que ele julgou de grande importância, acabou tomando uma enorme extensão no livro. São cerca de 200 páginas apresentando uma infinidade de informaçôes e dados sobre diferentes tipos de animais e sobre o homem, com uma enorme abundância de referências bibliográficas

Em síntese, podemos dizer que a sistemática seguida por Darwin para mostrar suas ideias sobre a origem e descendência do homem é a 
mesma que seguiu em relação à evolução geral das espécies. Ela se resume nestas palavras:

Aquele que deseja decidir se o homem é um descendente diferente de alguma forma pré-existente, provavelmente deveria primeiro indagar se o homem varia, por pouco que seja, na estrutura corporal e nas faculdades mentais; e, sendo assim, se as variações são transmitidas à sua descendência de acordo com as leis que prevalecem nos animais inferiores. (Darwin, 1871, p. 9-10)

\section{A expressão das emoçôes no homem e nos animais (1872)}

Não é difícil entender porque não fazia parte dos planos de Darwin escrever uma obra sobre $A$ expressão das emoções no homem e no animal quando, um ano antes, escrevera $A$ descendência do homem. Segundo ele mesmo diz (1872, p. 19), suas observações sobre a expressão das emoções começaram em 1838, mas depois só ocasionalmente voltou ao assunto, pois naquele tempo ele já estava inclinado a acreditar no princípio da evolução ou derivação das espécies de outras formas inferiores. A evolução do homem, portanto, estaria pressuposta, sendo que a teoria da expressão das emoções confirmaria a origem animal do homem, como afirma no último capítulo do livro:

Vimos que o estudo da teoria da expressão confirma, dentro de certos limites, a conclusão de que o homem é derivado de alguma forma animal inferior, e dá suporte à opinião da unidade específica e subespecífica das diversas raças; mas, até onde meu julgamento vale, tal confirmação foi absolutamente necessária. (1872, p. 367)

Entretanto, ao ler a grande obra de Charles Bell e deparar-se com a afirmação de que "o homem foi criado com certos músculos especialmente adaptados para a expressão dos seus sentimentos (feelings)", pareceu-lhe insatisfatório tal ponto de vista, porque era provável que isso fosse adquirido lentamente, tornando-se inato. O problema era descobrir como isso podia ter acontecido. Foi assim que ele decidiu voltar a um trabalho que, então, poderia ter sido concluído, mesmo que fosse de maneira imperfeita.

O tema da expressão das emoções é antigo. Durante os séculos que precederam à época de Darwin, séculos XVII e XVIII, foram publicados 
muitos livros, ${ }^{12}$ alguns dos quais ele leu e concluiu que eram de pouca ou nenhuma valia para o que ele se propunha. Trata-se, em efeito, de trabalhos que veem a emoção como uma questão fisionômica, ou seja, que se expressa através dos sinais do rosto. Embora esse tipo de estudos também fosse comum na época de Darwin, a diferença é terem um caráter mais científico, não apenas meramente intuitivo. As análises do fisiologista Charles Bell, apresentadas no seu livro Essay on the anatomy and philosophy of expression, de 1806, obra que Darwin considerou muito importante, justamente por introduzir no estudo das emoções a perspectiva científica, constituem uma espécie de protótipo do que se produzia sobre o assunto. O problema é que, como diz Darwin (1972, p. 10), "todos os autores que escreveram sobre expressão, com exceção de Herbert Spencer ${ }^{13}$ (1820-1903), o grande defensor do princípio da Evolução, parece que estão profundamente convencidos de que as espécies, incluído o homem, vêm à existência na sua condição presente". As explicações desses cientistas, como as de Bell, ${ }^{14}$ baseadas em elementos anatômicos e fisiológicos, se situam à margem da evolução. Em $A$ expressão das emoções, Darwin segue também esse caminho, cuidando de construir "princípios científicos" para analisar o grande volume de registros disponíveis e utilizando recursos metodológicos para "coletar os dados". O que a diferenciava de todas as obras sobre a expressão das emoções era seu objetivo de produzir a prova de que a evolução do homem é semelhante à das outras espécies.

Como mostram os trabalhos sobre as emoções no homem, surgidos entre o fim do século XIX e início do XX, os estudos puramente anatômico-fisionômicos a que se refere Darwin perderam o interesse, cedendo lugar às explicaçôes fisiológico-neurológicas. Três tipos principais desses "modelos" ocupam sucessivamente a cena: o de JamesLange (1884), o de Cânon-Bard (1929) e o de James Papez (1937). ${ }^{15}$ Em síntese, a diferença principal entre os dois primeiros está no caminho que segue a percepção de uma situação para produzir uma reação emocional. No modelo James-Lange, a percepção sensorial da situação provoca reações fisiológicas neurovegetativas, que produzem a sensação da reação emocional. Já no modelo Cânon-Bard, a percepção sensorial desencadeia um impulso nervoso que atinge o tálamo, estrutura subcortical, de onde parte um duplo sinal que atinge, simultaneamente, duas regiōes diferentes do cérebro: o hipotálamo, que desencadeia as reações fisiológicas, e o córtex cerebral, que produz os sentimentos 
emocionais que as acompanham. James Papez, por sua vez, sustenta que a emoção não é resultado de centros cerebrais específicos, mas de um circuito complexo que envolve diferentes estruturas cerebrais interligadas: o hipotálamo e seus corpos mamilares, o núcleo anterior do tálamo, o giro cingulado e o hipocampo. Este circuito integrado responde pelo mecanismo das funções centrais da emoção (afetos) e das funções periféricas (reações fisiológicas, sintomas da emoção).

\section{Conclusão: perseguindo linhas de reflexão para a educação}

Conforme foi dito na Introdução deste texto, seu objetivo é apontar algumas possíveis linhas de reflexão sobre a contribuição da obra de Darwin no campo da Educação, no duplo sentido em que esta é entendida aqui. Não é, portanto, escopo deste texto aprofundar as questões que essas linhas sugerem, mas apenas apontar algumas delas que possam indicar uma pauta para um possível "dossiê" sobre a temática da evolução.

Uma primeira linha de reflexão decorre da leitura de $A$ origem das espécies. Com efeito, tem-se a nítida impressão de que Darwin tinha consciência do terremoto que sua teoria provocaria, não só na Inglaterra puritana, mas também em outros lugares do Ocidente cristão. ${ }^{16}$ Tudo isso após um século em que a Revolução Francesa e a Revolução Industrial prenunciavam abalos nas estruturas do poder político e no pensamento tradicional sacudido pelo "ideário iluminista" - uma nova racionalidade, uma sociedade civil, um Estado laico e democrático, instituiçôes públicas laicas e direitos humanos. Uma pauta que permitia vislumbrar no horizonte a possibilidade de poder viver com liberdade de ideias e tolerância de confissóes religiosas. Ora, a publicação da obra de Darwin revelava que o efetivo foco das reações contrárias que ela provocou, e continua provocando dois séculos depois, é a resistência das ideologias fechadas, políticas e religiosas, hoje denominadas "fundamentalismos", à idéia de liberdade de pensamento. É a questão inescapável da relação - quase impossível - entre ciência e fé.

A segunda linha de reflexão é que, se o universo físico está num processo constante de mudança, no universo biológico essa mudança ocorre na forma de um processo de geração de novas formas de vida, em que as mais simples dão origem às mais novas. Esta pode ser a base 
de uma nova ética ecológica, decorrente do acesso ao conhecimento do modo de funcionamento desses dois universos.

A terceira linha de reflexão decorre da leitura do livro $A$ descendência do homem. Fazia parte do pensamento de Darwin - com as limitaçôes da época - e faz parte do pensamento científico contemporâneo - com os recursos técnicos de que ele dispóe - a idéia de que o homem é um ser vivo que evolui como todos os outros e que seu passado ancestral lembra as formas mais simples de vida. Metaforicamente, poderíamos dizer que ele é a "última geração de um ser vivo". Mas algo que parece que escapara a Darwin e, infelizmente, ainda escapa a certas áreas do pensamento contemporâneo é que, com o aparecimento do homem, a evolução continua seu curso, mas de uma forma nova: o homem tornou-se capaz de determinar o rumo de sua evolução e, indiretamente, o da natureza. Isso coloca o complexo problema da origem e fundamentos da consciência.

A quarta linha de reflexão decorre da leitura do livro $A$ expressão das emoçôes no homem e nos animais. É surpreendente a curiosidade científica de Darwin revelada nessa obra: de um lado, por procurar com ela provar sua teoria da evolução, quando a questão da emoção vinha sendo o objeto de tratados filosóficos, como a Ética, de Spinoza (1675), e as Paixóes da alma, de Descartes (1649); do outro, porque, querendo ou não, ele aponta a origem biológica dos sentimentos humanos que, na tradição racionalista e idealista, ficava do outro lado da razão.

A quinta linha de reflexão é que, se ao mostrar que o homem descende do animal, Darwin apontava algo que vai além das semelhanças fisiológicas com o mundo animal, escapava a ele, o que é razoável, qual seriam os limites entre uma biologia natural e uma biologia humana. Faltavam elementos para explicar porque esse homem que integra o fluxo evolutivo das espécies se distancia delas no que ele tem de especificamente humano. É algo que as pesquisas contemporâneas podem ajudar a explicar.

A sexta linha de reflexão decorre da articulação das ideias de dois dos livros de Darwin com as de $A$ descendência do homem. Trata-se do que faltava à teoria da evolução de Darwin e que as novas pesquisas em diferentes campos das ciências, naturais e humanas, podem ajudar a pensar. O desenvolvimento tecnológico abriu novas perspectivas para as pesquisas no campo das ciências em geral e, mais especificamente, 
no da biogenética - com o sequenciamento do genoma humano (2001) e de outras espécies e com a possibilidade de intervenção nesses genomas, graças à engenharia genética - e das neurociências. Com isso, ficaram postas as condiçóes para possibilitar uma melhor compreensão da natureza humana do homem. Todavia, cremos que isso ainda não é suficiente, pois se corre o risco de ficar puramente no plano das funçôes biológicas mais elementares. Como diz Damásio, falando da emoção: "a ciência deixou o corpo de lado, devolveu a emoção ao cérebro, mas relegou-a aos estratos neuronais inferiores, associados a ancestrais que ninguém venerava" (2004, p. 60).

A sétima linha de reflexão decorre da necessidade de ir além dos atuais limites da biogenética e da neurologia, da paleontologia e da etnologia, da antropologia e da psicologia e de outras ciências, para pensar o homem como um ser completo. Um caminho possível, não o único, nós é dado pelo "materialismo histórico e dialético" de Marx e Engels, traduzido na nova visão do ser humano presente nos trabalhos de Vigotski (1997) e Vigotski e Luria (1991), entre outros. Nesses trabalhos, redescobrimos o homem completo, um ser que, emergindo no fluxo evolutivo da vida, de um longo e ancestral passado biológico, ascendeu na escala animal, fazendo das funçôes biológicas herdadas o suporte das novas funçôes culturais e simbólicas que ele construiu e continua construindo no confronto com a natureza de que ele faz parte. Nessa grande tarefa, todas as ciências estão convocadas para construírem, juntas, a imagem humana do homem.

Recebido em agosto de 2009 e aprovado em setembro de 2009.

\section{Notas}

1. As obras de Charles Darwin usadas no texto estão disponíveis em The complete works of Charles Darwin online (http://darwin-online.org.ku).

2. A denominação "Ciências Humanas", em contraposição à de "Ciências Naturais", foi consolidando-se ao longo do século XIX, principalmente com a obra do filósofo alemão Wilhelm Dilthey (1833-1911), interessado em desenvolver uma metodologia para as humanidades de tipo compreensivo (Verstchen), diferente da metodologia explicativa (Erklaren) da ciência. Isso o levou a procurar fundamentar filosoficamente o que ele denominou de Geisteswissenschaften, como aparece na sua obra Einleitung in die Geisteswissenschaften (Introdução às Ciências Humanas), de 1883, às quais M. Foucault (1992, p. 361) se refere como "esse corpo de conhecimentos (...) que toma por objeto o homem no que ele tem de empírico". 
3. Neste trabalho é utilizado o adjetivo humano(a) em itálico, para ressaltar a dupla dimensão biológica e cultural específica da natureza do homem.

4. Disponível em: <http://www.ditudo.wiki.br/Alfred_Russel_Wallace.html>.

5. Disponível em: <http://www.ditudo.wiki.br/Thomas_Henry_Huxley.html>.

6. O "uniformitarismo" é uma teoria geológica, de inspiração criacionista, que entende que as mudanças geofísicas ocorrem de maneira gradual, contrariamente à teoria do "catastrofismo", ambas constituindo variantes da teoria criacionista. O princípio fundamental é que as mudanças geológicas do passado se explicam pelos processos geológicos em ação no presente, os quais são diretamente observáveis.

7. "In considering the Origin of Species, it is quite conceivable that a naturalist, reflecting on the mutual affinities of organic beings, on their embryological relations, their geographical distribution, geological succession, and other such facts, might come to the conclusion that each species had not been independently created, but had descended, like varieties, from other species. Nevertheless, such a conclusion, even if well founded, would be unsatisfactory, until it could be shown how the innumerable species inhabiting this world have been modified, so as to acquire that perfection of structure and coadaptation which most justly excites our admiration".

8. "I can entertain no doubt, after the most deliberate study and dispassionate judgment of which I am capable, that the view which most naturalists entertain, and which I formerly entertained - namely, that each species has been independently created - is erroneous".

9. "I am fully convinced that species are not immutable; but that those belonging to what are called the same genera are lineal descendants of some other and generally extinct species, in the same manner as the acknowledged varieties of any one species are the descendants of that species. Furthermore, I am convinced that Natural Selection has been the main but not exclusive means of modification".

10. I should premise that I use the term Struggle for Existence in a large and metaphorical sense, including dependence of one being on another, and including (which is more important) not only the life of the individual, but success in leaving progeny"(1857, p. 62).

11. “personne, en Europe au moins, n’ose plus soutenir la crèation indèpendante et de toutes pièces, des espèces”.

12. Darwin se refere a um artigo de J. Parsons (in: Philosophical Transactions, 1746, p. 41), que dá uma lista de mais de 40 obras.

13. Cf. Spencer (1855).

14. Cf. Bell (1810, p. 98, 121, 131; citado por Darwin, 1872, p. 10).

15. Os dois primeiros modelos são conhecidos por essa denominação por sintetizar as concepçôes muito parecidas de cada um dos dois cientistas a respeito da teoria da emoção; concepções próximas ou complementares.

16. Isso faz lembrar as célebres palavras que S. Freud teria proferido na abertura das suas "Conferências", na Clark University (1009), nos Estados Unidos: "Eu vos trago a peste”. 


\section{Referências}

BELL, C. Essay on the anatomy and philosophy of expression. London: Longmans, 1806.

BUFFON, G. Histoire naturelle, générale et particulière. Paris, 17491788. $44 \mathrm{v}$.

BUFFON, G. Oeuvres complètes. Paris: Robert Libraire, 1853-1855. $12 \mathrm{v}$.

CAILLOIS, R. L'homme et le sacré. 3. ed. Paris: Gallimard, 1963.

CAILLOIS, R. Le mythe et l'homme. Paris: Gallimard, 1972.

DAMASIO, A. O erro de Descartes. São Paulo: Cia das Letras, 2003.

DAMASIO, A. O mistério da consciência. 5. ed. São Paulo: Cia das Letras, 2004.

DARWIN, C. On the origin of species by means of natural selection. London: John Murray, 1859.

DARWIN, C. The descent of man and selection in relation to sex. London: John Murray, 1871.

DARWIN, C. The expression of the emotions in man and animals. London: John Murray, 1872.

DARWIN, C. The foundations of the origin of species: two essays written in 1842 and 1844. Cambridge: Cambridge University, 1909.

DARWIN, C. Voyage of the Beagle. London: Penguin, 1989.

ELIADE, M. Aspects du mythe. Paris: Gallimard, 1963.

ENCICLOPAEDIA BRITANNICA. Darwin, Charles. 15. ed. Chicago: William Benton, 1978. v. 5, p. 492-496.

ENCICLOPAEDIA BRITANNICA. Evolution. 15. ed. Chicago: William Benton, 1978. v. 7, p. 7-23.

FOUCAULT, M. As palavras e as coisas. Trad. bras. São Paulo: Martins Fontes, 1992. 
GIRARD, R. La violence et le sacré. Paris: Grasset, 1972

LINNAEUS, C. Enciclopaedia Britannica. 15. ed. Chicago: William Benton, 1978. v. 10, p. 1013.

MAKARIUS, L.L. Le sacré et la violation des interdits. Paris: Payot, 1974.

MAYR, E.W. The growth of biological thought. Cambridge, Mass: Harvard University, 1981.

SPENCER, H. Principles of psychology. London: Longmans, 1855.

VIGOTSKI, L.S. The history of development of higher mental functions. In: Vigotski, L.S. The collected works. New York: Plenun, 1997. v. 4.

VIGOTSKI, L.S.; LURIA, A.R. Studies of the history of behavior: ape, primitive and child. Edited and translated by I. Golod and Jane E Knox. New York: Lawrence Erlbaum, 1992. 